\title{
Determination of fatty acid ethyl esters in dried blood spots by LC-MS/MS as markers for ethanol intake: application in a drinking study
}

\author{
Marc Luginbühl $^{1}$ - Alexandra Schröck ${ }^{1} \cdot$ Stefan König $^{1} \cdot$ Stefan Schürch $^{2}$. \\ Wolfgang Weinmann ${ }^{1}$
}

Received: 4 December 2015 / Revised: 5 February 2016 / Accepted: 16 February 2016

(C) Springer-Verlag Berlin Heidelberg 2016

\begin{abstract}
The forensic utility of fatty acid ethyl esters (FAEEs) in dried blood spots (DBS) as short-term confirmatory markers for ethanol intake was examined. An LC-MS/MS method for the determination of FAEEs in DBS was developed and validated to investigate FAEE formation and elimination in a drinking study, whereby eight subjects ingested $0.66-$ $0.84 \mathrm{~g} / \mathrm{kg}$ alcohol to reach blood alcohol concentrations (BAC) of $0.8 \mathrm{~g} / \mathrm{kg}$. Blood was taken every $1.5-2 \mathrm{~h}$, BAC was determined, and dried blood spots were prepared, with $50 \mu \mathrm{L}$ of blood, for the determination of FAEEs. Lower limits of quantitation (LLOQ) were between 15 and $37 \mathrm{ng} / \mathrm{mL}$ for the four major FAEEs. Validation data are presented in detail. In the drinking study, ethyl palmitate and ethyl oleate proved to be the two most suitable markers for FAEE determination. Maximum FAEE concentrations were reached in samples taken 2 or $4 \mathrm{~h}$ after the start of drinking. The following mean peak concentrations $\left(c_{\max }\right)$ were reached: ethyl myristate $14 \pm 4 \mathrm{ng} /$ $\mathrm{mL}$, ethyl palmitate $144 \pm 35 \mathrm{ng} / \mathrm{mL}$, ethyl oleate $125 \pm 55 \mathrm{ng} /$ $\mathrm{mL}$, ethyl stearate $71 \pm 21 \mathrm{ng} / \mathrm{mL}$, total FAEEs $344 \pm 91 \mathrm{ng} /$ $\mathrm{mL}$. Detectability of FAEEs was found to be on the same time scale as BAC. In liquid blood samples containing ethanol, FAEE concentrations increase post-sampling. This study
\end{abstract}

Electronic supplementary material The online version of this article (doi:10.1007/s00216-016-9426-y) contains supplementary material, which is available to authorized users.

Marc Luginbühl

marc.luginbuehl@irm.unibe.ch

1 Institute of Forensic Medicine, University of Bern, Bühlstrasse 20, 3012 Bern, Switzerland

2 Department of Chemistry and Biochemistry, University of Bern, Freiestrasse 3, 3012 Bern, Switzerland shows that the use of DBS fixation prevents additional FAEE formation in blood samples containing ethanol. Positive FAEE results obtained by DBS analysis can be used as evidence for the presence of ethanol in the original blood sample.

Keywords Fatty acid ethyl ester - Alcohol marker . Abstinence monitoring $\cdot$ Whole blood $\cdot$ LC-MS/MS $\cdot$ Dried blood spots

\section{Introduction}

Alcohol abuse and its medical and social effects pose a major challenge in today's society. In order to prove alcohol abstinence, various secondary alcohol markers are currently analyzed in blood, urine, and hair, such as ethyl glucuronide (EtG), ethylsulfate (EtS), and phosphatidylethanol (PEth) [1]. Fatty acid ethyl esters (FAEEs) are non-oxidative shortterm metabolites that are generally not included in routine analysis [2]. FAEE metabolites are detectable in blood when ethanol is present and up to $24 \mathrm{~h}$ after alcohol intake [3]. FAEE formation is mainly catalyzed by FAEE synthases and acylCoA:ethanol $O$-acyltransferases (AEAT), which form FAEEs by esterification of ethanol with endogenous fatty acids or fatty acyl-CoA. As a result of their chemical structure, FAEEs have a tendency to bind to albumin and lipoproteins, both of which serve as transporters between different lipid compartments. Although at least 15 different FAEEs have been identified in the human body, four FAEEs in particular are used as ethanol consumption-related markers: ethyl myristate (14:0), ethyl palmitate (16:0), ethyl stearate (18:0), and ethyl oleate (18:1). Until recently, the detection of FAEEs was predominantly based on GC/MS and SPME-GC/MS methods for hair samples and meconium, whereby the total FAEE concentration was summed up [1,2]. Analysis of 
FAEEs by using LC-MS/MS was first published in 2014, whereby in utero ethanol exposure in meconium was identified [4]. This paper provides detailed profiles of the four particular FAEEs during a drinking study and can be compared to the work of Doyle et al. [3], where the total FAEE concentration in relation to the blood alcohol concentration was investigated. However, our dried blood spots (DBS) method prevents FAEE formation post-sampling and exhausts the potential of present-day instrumentation by using low sample volume. LC-MS/MS was the method of choice, as SPME-GC/ MS and GC/MS could not provide the required sensitivity, when only using microliter amounts of blood. Furthermore, endogenous fatty acid concentrations were detected and quantified by using linear regression.

\section{Materials and methods}

\section{Reagents}

Ethyl myristate, ethyl palmitate, and ethyl stearate were purchased from Lipomed (Arlesheim, Switzerland). Ethyl oleate (98\%) was obtained from Sigma Aldrich (Buchs, Switzerland). Pentadeuterated internal standards $\mathrm{D}_{5}$-ethyl myristate, $\mathrm{D}_{5}$-ethyl palmitate, $\mathrm{D}_{5}$-ethyl stearate, and $\mathrm{D}_{5}$-ethyl oleate were ordered from Toronto Research Chemicals (Toronto, Canada). HPLC-grade acetonitrile $(\mathrm{MeCN})$ for gradient analysis was purchased from Acros Organics (New Jersey, USA) and water was produced in-house with a MilliQ water system from Millipore (Billerica, USA). Dried dimethyl sulfoxide (DMSO) (max. $0.05 \% \mathrm{H}_{2} \mathrm{O}$, purity $\geq 99.5 \%$ ) and EMSURE $^{\circledR} n$-heptane for analysis (>99\%) were obtained from Merck (Darmstadt, Germany). Pure HPLC-grade ethanol was obtained from Merck (Darmstadt, Germany). Formic acid puriss. p.a. for HPLC ( $50 \%$ in water) and Whatman ${ }^{\circledR} \# 903 \mathrm{CF} 12^{\circledR}$ protein saver paper were ordered from Sigma Aldrich (Buchs, Switzerland). Anticoagulant citrate phosphate dextrose (CPD)-treated blank whole blood for the calibration and the quality control samples was delivered from the local blood collection center (Bern, Switzerland). The anticoagulant lithium heparin was used to obtain whole blood samples during the drinking study.

\section{Study design}

Eight volunteers (6 men, 2 women, aged 19-26 years), who had been abstinent for at least 2 weeks, ingested a single dose of alcohol (66-proof $/ 37.5 \%$ vodka mixed with a soft drink), which led to an approximate BAC of $0.8 \mathrm{~g} / \mathrm{kg}$. The alcohol doses $(125-210 \mathrm{~mL})$ were calculated for each test person by the Widmark formula with individually adjusted reduction factors based on the weight and size of the individual [5]. Blank blood samples were obtained from all subjects prior to the experiment. The first blood sample was taken $100 \mathrm{~min}$ after the start of drinking. Three more samples were taken during the next $5 \mathrm{~h}$. All blood samples were directly spotted on protein saver filter paper to create the DBS.

\section{Sample preparation}

FAEEs were analyzed in DBS generated from lithium heparinized blood by spotting $50 \mu \mathrm{L}$ of blood onto a Whatman ${ }^{\circledR}$ \#903 CF $12^{\circledR}$ protein saver paper. Before extraction, the DBS were dried at room temperature for at least $3 \mathrm{~h}$.

\section{Determination of BAC}

BAC was determined in lithium heparinized blood by a validated headspace gas chromatography method with flame ionization detection (HS-GC-FID). According to Swiss forensic guidelines, the samples were analyzed with two GC-FID systems with two measurements each, analogously to BAC determination in serum [6].

\section{Determination of FAEEs}

For analyzing ethyl myristate (C14), ethyl palmitate (C16), ethyl oleate (C18:1), and ethyl stearate (C18), a DBS generated from $50 \mu \mathrm{L}$ of blood was cut out and $20 \mu \mathrm{L}$ of internal standard (D ${ }_{5}$-ethyl myristate (C14) $75 \mathrm{ng} / \mathrm{mL}, \mathrm{D}_{5}$-ethyl palmitate (C16) $62.5 \mathrm{ng} / \mathrm{mL}, \mathrm{D}_{5}$-ethyl oleate $(\mathrm{C} 18: 1) 125 \mathrm{ng} / \mathrm{mL}$, and $\mathrm{D}_{5}$-ethyl stearate (C18) $62.5 \mathrm{ng} / \mathrm{mL}), 500 \mu \mathrm{L}$ of DMSO, and $1000 \mu \mathrm{L} n$ heptane were pipetted into a microtube and mixed for $20 \mathrm{~min}$ at $1500 \mathrm{rpm}$ on a VIBRAX VXR basic from IKA (Staufen, Germany). Afterwards, the samples were centrifuged for $10 \mathrm{~min}$ at $16,000 \times \mathrm{g}$. The samples were placed in a freezer at about $-18^{\circ} \mathrm{C}$ for $30 \mathrm{~min}$ to congeal the DMSO and simplify the transfer of the supernatant to a $1.5-\mathrm{mL}$ snap/crimp champagne glass vial. The organic phase was evaporated until dry at $60^{\circ} \mathrm{C}$ under vacuum (approximately $180 \mathrm{mbar}$ ) with a CentriVap concentrator from $\mathrm{LABCONCO}^{\circledR}$ (Biolabo Scientific Instruments, Switzerland). The residue was dissolved in $300 \mu \mathrm{L}$ acetonitrile. An aliquot of $5 \mu \mathrm{L}$ was injected into the LC-MS/MS system. A blank (whole blood from an abstinent person without internal standard) and a zero sample (whole blood from an abstinent person with internal standard) were always included.

\section{FAEE in vitro production}

A 5-mL portion of fresh, lithium heparinized blood was spiked immediately after sampling with $6.3 \mu \mathrm{L}, 12.6 \mu \mathrm{L}$, and $18.9 \mu \mathrm{L}$ ethanol to obtain a BAC of 1,2 , and $3 \mathrm{~g} / \mathrm{kg}$ ( $\pm 0.05 \mathrm{~g} / \mathrm{kg}$ ), respectively. After spiking, the blood was incubated at $37^{\circ} \mathrm{C}$ and a $50 \mu \mathrm{L}$ DBS was generated every $10 \mathrm{~min}$ during the first hour to monitor FAEE production. The blank sample at $t=0$ did not contain any alcohol. 
Table 1 MS/MS parameters and retention time for FAEEs quantitation from DBS

\begin{tabular}{llllllll}
\hline Analyte & Q1 $(m / z)$ & Q3 $(m / z)$ & Time $(\mathrm{ms})$ & DP $(\mathrm{V})$ & CE $(\mathrm{V})$ & CXP $(\mathrm{V})$ & RT $(\mathrm{min})$ \\
\hline Ethyl myristate & 257.2 & 229.2 & 30 & 85 & 15 & 20 & 3.27 \\
& 257.2 & 103 & 30 & 85 & 22 & 12 & \\
& 257.2 & 247.2 & 30 & 85 & 10 & 22 & \\
Ethyl myristate- $d_{5}$ & 262.2 & 230.3 & 20 & 81 & 15 & 16 & 3.26 \\
Ethyl palmitate & 285.1 & 257.3 & 30 & 41 & 15 & 22 & 3.74 \\
& 285.1 & 71.1 & 30 & 41 & 21 & 34 & \\
Ethyl palmitate- $d_{5}$ & 290.3 & 258.4 & 20 & 86 & 17 & 12 & 3.72 \\
Ethyl oleate & 311.2 & 265.3 & 30 & 100 & 15 & 24 & 3.86 \\
& 311.2 & 247.2 & 30 & 100 & 17 & 20 & \\
Ethyl oleate- $d_{5}$ & 316.3 & 265.4 & 20 & 86 & 15 & 22 & 3.84 \\
Ethyl stearate & 313.1 & 285.3 & 30 & 46 & 17 & 22 & 4.21 \\
& 313.1 & 71.1 & 30 & 36 & 25 & 10 & \\
Ethyl stearate- $d_{5}$ & 318.3 & 286.2 & 20 & 56 & 17 & 22 & 4.20 \\
\hline
\end{tabular}

\section{Method validation}

Method validation for the determination of FAEEs in DBS was performed according to US Food and Drug Administration (FDA) guidelines with a standard addition correction for endogenous levels [7]. Selectivity, linearity, limit of quantification, imprecision (expressed as the relative standard deviation, RSD \%), accuracy (expressed as the mean relative error, RE \%), and carry-over were investigated. Selectivity was determined by testing six blank samples of blood from alcohol abstinent people (abstinence period of more than 2 weeks) and from swine for interferences of endogenous matrix components or metabolites, which could disturb the signals of FAEEs or internal standards. Additionally, the feasibility of a standard addition-based method was investigated, by using blank blood from an abstinent subject. CPDtreated blood from an abstinent person was used for calibration and quality control samples. Working solutions containing all four FAEEs $(0.2,0.4,1,2,5,10,15,20$, and $40 \mu \mathrm{g} / \mathrm{mL})$ for the calibration samples were prepared in acetonitrile and $10 \mu \mathrm{L}$ of each was spiked in $190 \mu \mathrm{L}$ of blank blood. The calibrators had the following concentrations: $10,20,50,100$, $250,500,750,1000$, and $2000 \mathrm{ng} / \mathrm{mL}$. Nine-point calibration curves of FAEEs were recorded twice on three different days. Precision and accuracy were determined by preparing blood samples (quality control samples, QC) spiked at different FAEE concentration levels: 10, 20, 30, 50, 150, 600, and $1500 \mathrm{ng} / \mathrm{mL}$. Carry-over was measured by injecting the highest calibrator $(2000 \mathrm{ng} / \mathrm{mL})$ three times, followed by a blank blood sample in duplicate to test if substances from the previous injection were carried over to the next measurement. Matrix effects, recovery, and extraction efficiency were analyzed by post-extraction addition. Corrections for endogenous FAEE concentrations were made at the end of the measurement by correcting for the absolute value of the $x$-axis intercept from the individual calibration curve.

\section{Instrumentation}

The LC-MS/MS system was composed of an UltiMate ${ }^{\circledR} 3000$ UHPLC + focused system with an UltiMate ${ }^{\circledR} 3000$ RS

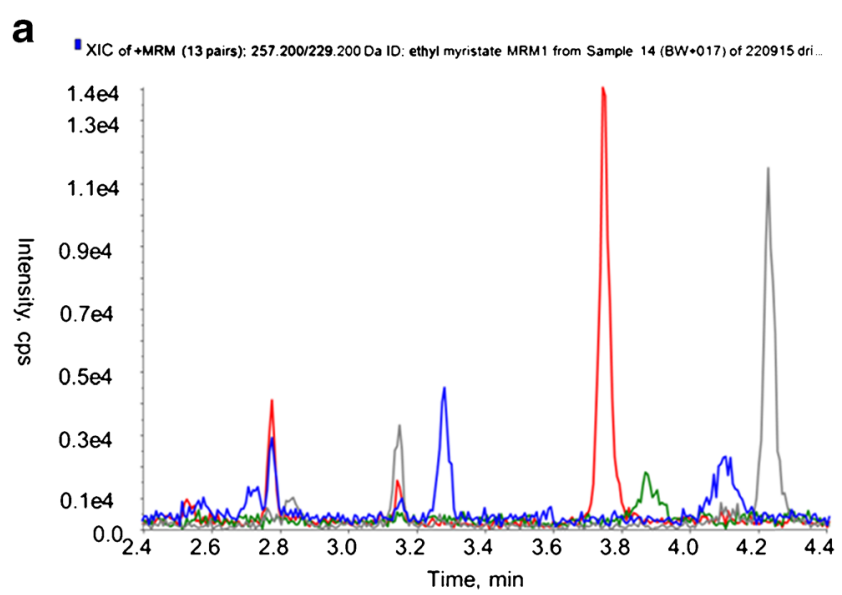

b

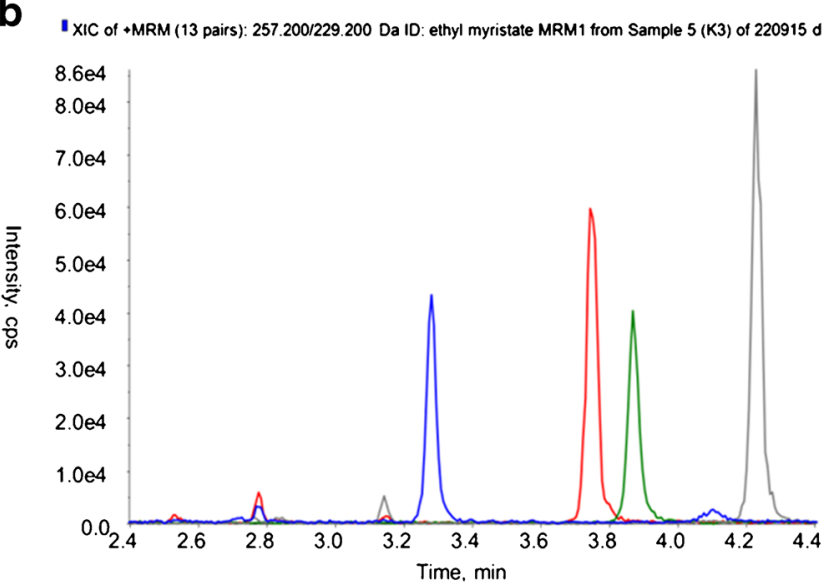

Fig. 1 Typical chromatogram of blank whole blood (a) and whole blood spiked with K3 (50 ng/mL) (b). MRM1: ethyl myristate (blue), ethyl palmitate (red), ethyl oleate (green), and ethyl stearate (gray) 
autosampler and a heated column compartment from Dionex (Olten, Switzerland) with a QTrap 5500 mass spectrometer from Sciex (Toronto, Canada), controlled by Analyst 1.6.2 software. Chromatographic separation was performed with a coreshell Kinetex $2.6 \mu \mathrm{m}, \mathrm{C} 8,100 \AA, 50 \times 2.1 \mathrm{~mm}$ column from Phenomenex (Torrance, USA), heated at $40^{\circ} \mathrm{C}$, with a flow rate of $0.5 \mathrm{~mL} / \mathrm{min}$. Mobile phase A consisted of water with $0.1 \%$ formic acid, mobile phase B consisted of acetonitrile with $0.1 \%$ formic acid. The FAEEs, depicted in Table 1, were analyzed with the following 8 min gradient: 0 to $0.5 \mathrm{~min}, 20 \% \mathrm{~B}$; 0.5 to $1.5 \mathrm{~min}, 20$ to $70 \% \mathrm{~B}$ linear; 1.5 to $5 \mathrm{~min}, 70$ to $97.5 \% \mathrm{~B}$ linear; 5 to $6 \mathrm{~min}, 97.5 \% \mathrm{~B}$; 6 to $6.1 \mathrm{~min} 97.5$ to $20 \% \mathrm{~B}$ linear, 6.1 to $8 \mathrm{~min}, 20 \% \mathrm{~B}$. The mass spectrometer was operated in electrospray positive MRM mode with the following parameters: ion spray voltage, $5000 \mathrm{~V}$; source temperature, $650{ }^{\circ} \mathrm{C}$; collision gas at medium 40; curtain gas, 40; gas 1, 40; gas 2, 40 .

\section{Results and discussion}

\section{Method validation}

Regarding selectivity, the measured samples had to be corrected for endogenous FAEE concentrations to obtain valid results, as there was no blood available which did not contain any FAEEs. Extracted ion chromatograms for a blank blood


Fig. 2 Detailed chromatogram for ethyl myristate (a), ethyl palmitate (b), ethyl oleate (c), and ethyl stearate (d) at concentration K3 with MRM1 (blue), MRM2 (red) and internal standard (green) 
Table 2 Extraction efficiency, recovery, and matrix effect for FAEEs in DBS

\begin{tabular}{|c|c|c|c|c|c|c|}
\hline \multirow[t]{2}{*}{ Analyte } & \multicolumn{2}{|c|}{$\begin{array}{l}\text { Extraction } \\
\text { efficiency }(n=2)\end{array}$} & \multicolumn{2}{|c|}{$\begin{array}{l}\text { Recovery } \\
(n=2)\end{array}$} & \multicolumn{2}{|c|}{$\begin{array}{l}\text { Matrix effect } \\
(n=2)\end{array}$} \\
\hline & Low $^{\mathrm{a}}$ & $\operatorname{High}^{\mathrm{b}}$ & Low & High & Low & High \\
\hline Ethyl myristate & $40 \%$ & $45 \%$ & $40 \%$ & $42 \%$ & $99 \%$ & $93 \%$ \\
\hline Ethyl palmitate & $55 \%$ & $60 \%$ & $51 \%$ & $63 \%$ & $93 \%$ & $105 \%$ \\
\hline Ethyl oleate & $59 \%$ & $61 \%$ & $55 \%$ & $62 \%$ & $96 \%$ & $101 \%$ \\
\hline Ethyl stearate & $59 \%$ & $69 \%$ & $67 \%$ & $75 \%$ & $113 \%$ & $110 \%$ \\
\hline
\end{tabular}

${ }^{\mathrm{a}}$ Low QC concentration was $50 \mathrm{ng} / \mathrm{mL}$ for all FAEEs

${ }^{\mathrm{b}}$ High QC concentration was $600 \mathrm{ng} / \mathrm{mL}$ for all FAEEs

$14.6 \%$ and interassay imprecision was $0.6-14.3 \%$ (see Electronic Supplementary Material (ESM), Table S1).

No evidence for carry-over was found. All FAEEs demonstrated adequate extraction efficiency of 40-69\%, recovery was $40-75 \%$, and FAEE matrix effects were $93-113 \%$ (Table 2). Extracted samples were stable up to $72 \mathrm{~h}$ in the autosampler, after three freeze-thaw cycles at about $-18{ }^{\circ} \mathrm{C}$, and after storage for 7 days at about $-18{ }^{\circ} \mathrm{C}$. However, after extended storage (7 days) at room temperature, QC samples (prepared as DBS) showed a large variation of measured concentrations, compared to samples prepared and analyzed on day 0 . QC showed increases (up to $41 \%$ ) and decreases (up to $-52 \%$ ) of the FAEE concentrations. This finding implies that the long-term stability of analytes has to be taken into account. DBS samples collected during the drinking study were within $\pm 13 \%$ of immediate measurement when extracted after 1 week of storage (samples and calibrators stored at room temperature). As a result of the observed instability, DBS were extracted within $24 \mathrm{~h}$ after their generation. Furthermore, samples which were analyzed and compared together (quality control, calibration, drinking study) were always prepared and extracted simultaneously.

\section{In vitro FAEE production}

After the addition of ethanol, FAEE levels above the LLOQ were obtained for all four FAEEs. The biggest alcohol concentration-related increase in FAEE concentration was observed for ethyl palmitate and ethyl oleate. After $30 \mathrm{~min}$, FAEE concentrations above the LLOQ were reached for all concentrations of alcohol. Ethyl stearate concentrations above the LLOQ were found for samples containing at least $2 \mathrm{~g} / \mathrm{kg}$ of BAC and after 210 min only. Ethyl myristate showed concentrations above the LLOQ for all three alcohol concentrations after $50 \mathrm{~min}$, whereby no distinction was possible concerning the alcohol concentration spiked to the sample. Detailed time courses for the increase in in vitro FAEE concentrations are shown in Fig. 3. This in vitro experiment clearly demonstrated the necessity of immediate DBS fixation to measure FAEE concentrations reliably.

\section{Drinking study results}

The group of participating volunteers was very homogenous in age and body mass index (BMI) with a mean age of 23.5 \pm 2.4 years (range 19-26 years) and a BMI of $21.3 \pm 2.5 \mathrm{~kg} / \mathrm{m}^{2}$ (range $17.7-25.1 \mathrm{~kg} / \mathrm{m}^{2}$ ). All blood samples collected prior to
Fig. 3 Time courses for in vitro fatty acid ethyl ester (FAEE) concentrations for the four investigated substances over a time period of $210 \mathrm{~min}$ after spiking the blood for BAC of 1,2 , and $3 \mathrm{~g} / \mathrm{kg}$
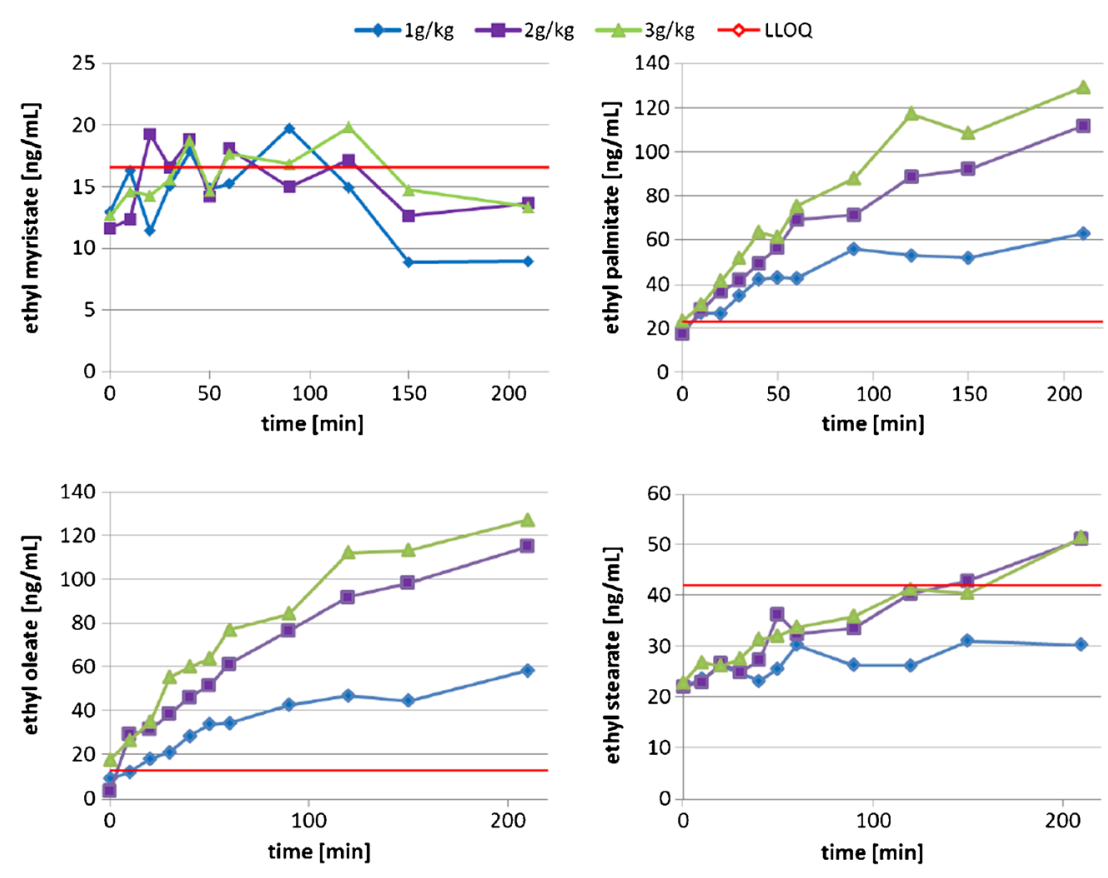
drinking tested negative for ethanol and below or close to the LLOQ for all FAEEs. Maximum BACs were reached $1.75 \mathrm{~h}$ after the start of drinking with a mean maximum BAC of 0.76 $\pm 0.06 \mathrm{~g} / \mathrm{kg}$ (range $0.66-0.84 \mathrm{~g} / \mathrm{kg}$ ). After drinking the calculated amounts of vodka, the following mean maximal concentrations were reached: ethyl myristate $\overline{c_{\max }}=14 \pm 4 \mathrm{ng} / \mathrm{mL}$, ethyl palmitate $\overline{c_{\text {max }}}=144 \pm 35 \mathrm{ng} / \mathrm{mL}$, ethyl oleate $\overline{c-}$ $\max =125 \pm 55 \mathrm{ng} / \mathrm{mL}$, and ethyl stearate $\overline{c_{\max }}=71 \pm 21 \mathrm{ng} /$ $\mathrm{mL}$, total FAEEs $\overline{c_{\max }}=344 \pm 91 \mathrm{ng} / \mathrm{mL}$. Figure 4 shows the time courses of each subject. There was a significant overlap between the curves for BAC and FAEE concentration over the time course. The peaks of the BAC and FAEE concentrations were found to be very close. Subjects 1-7 showed similar FAEE profiles and subject 8 showed delayed formation of FAEE. As shown in the in vitro experiments, FAEE formation started immediately after alcohol ingestion and increased to a maximum during the first $4 \mathrm{~h}$. After $4 \mathrm{~h}$ the concentration of FAEEs in the blood decreased. FAEE concentrations around the LLOQ were observed after $7 \mathrm{~h}$, when BAC reached zero. Although the concentrations for all FAEEs in all the subjects' samples increased after the consumption of alcohol, only five participants reached ethyl myristate levels above the LLOQ. Ethyl palmitate and ethyl oleate showed the highest increase. In comparison, ethyl stearate, with a relatively high LLOQ of $37 \mathrm{ng} / \mathrm{mL}$, showed concentrations above the LLOQ only for a short time. Detailed time courses for BAC and FAEE concentrations in different subjects are depicted in Fig. 4. FAEE concentrations above the endogenous level were not detected after 24 or $48 \mathrm{~h}$.
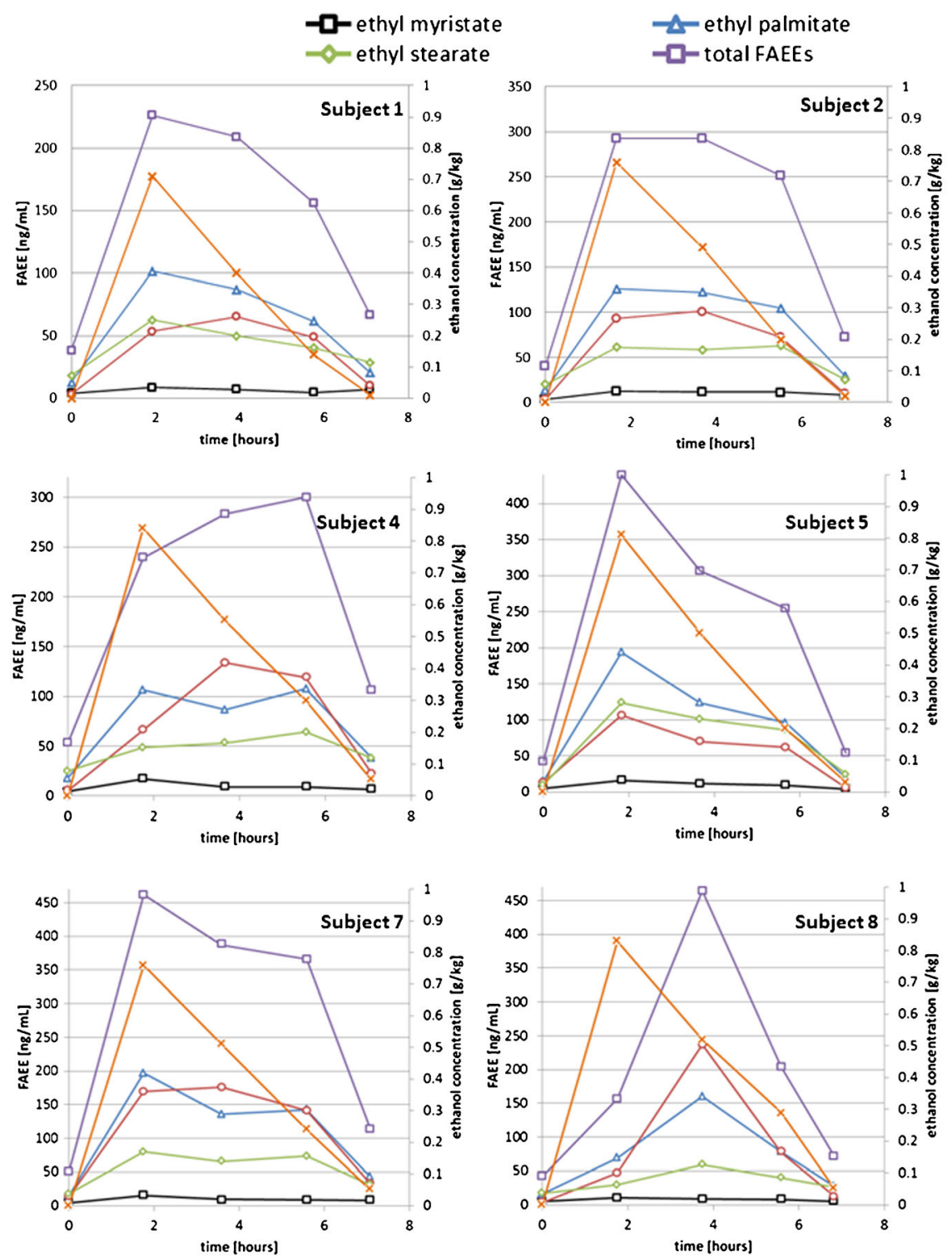
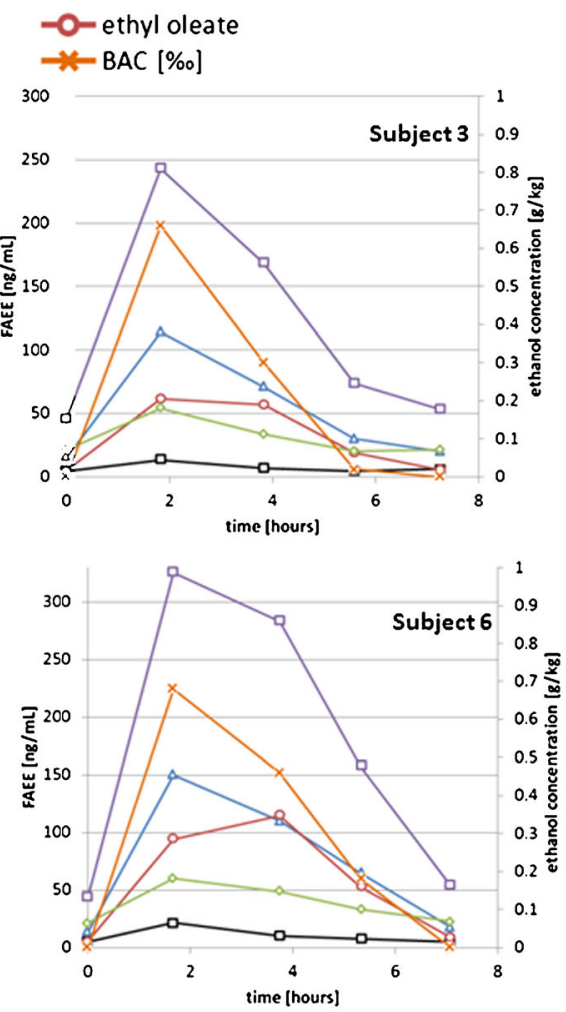

$\int^{1}$ $0.7 \stackrel{\bar{\Phi}}{\stackrel{5}{*}}$ 0.6 을 $0.5 \stackrel{5}{\mathrm{~K}}$ 0.3 옳

$$
\text { (1) }
$$




\section{Conclusion}

The results of this study indicate that whole blood DBS FAEE analysis may be useful as a short-term confirmation for ethanol ingestion or in the absence of liquid samples (e.g., blood spots at crime scenes). However, matrix samples without blood contamination would need further investigation (as a control sample) and further method validation would be necessary [8]. Especially during PEth analysis [9,10], where DBS fixation proved to be beneficial to prevent in vitro formation, FAEE analysis could serve as a second alcohol marker to monitor recent alcohol consumption. The detectability of FAEE concentrations in blood was found to be very similar to those of ethanol. A terminal half-life, which would allow detection for up to $24 \mathrm{~h}$ [3], was not found with a target BAC of $0.8 \mathrm{~g} / \mathrm{kg}$. Endogenous FAEE concentrations were observed and quantified using the standard addition method. Ethyl palmitate and ethyl oleate appeared to be the two most useful FAEEs, as concentrations above the LLOQ are easily reached. The application of DBS in FAEE analysis provides a safe and easy method to inhibit in vitro FAEE formation. Furthermore extraction is simplified when using DBS, as no timeconsuming SPE is needed, compared to analysis in blood serum with GC/MS [3]. The use of a LC-MS/MS method proved to be beneficial compared to preliminary tests with GC/MS [3] and SPME-GC/MS [11] methods, which could not provide the same sensitivity. In addition, the run-time of an LC-MS/MS measurement $(8 \mathrm{~min})$ is about four times faster than an SPME-GC/MS method (extraction of 20-30 min and analysis of $10 \mathrm{~min}$ ). [12] Further studies are necessary to investigate the relationship between blood fatty acid content and the formation of FAEEs.

Acknowledgments We would like to thank Sidonia Guggisberg, Anita Iannone, Anja Kaiser, Severine Krönert, Nadja Utiger, and Thomas Wüthrich of the Forensic Toxicology and Chemistry Laboratory of the Institute of Forensic Medicine Bern for the determination of blood alcohol concentrations.

Compliance with ethical standards The drinking study was approved by the Cantonal Ethics Commission Bern (064/13) on 3 March 2014.

Funding The drinking study and one of the authors (A.S.) was supported by the Swiss Foundation of Alcohol Research (Grant 254/2014:
Studies on phosphatidylethanol (PEth) - a promising biomarker for the detection of harmful ethanol consumption - and its possible use for abstinence monitoring).

Conflict of interest The authors declare that they have no conflict of interest.

\section{References}

1. Schrock A et al. Progress in monitoring alcohol consumption and alcohol abuse by phosphatidylethanol. Bioanalysis. 2014;6:228594.

2. Best CA, Laposata M. Fatty acid ethyl esters: toxic non-oxidative metabolites of ethanol and markers of ethanol intake. Front Biosci. 2003;1:e202-17.

3. Doyle KM et al. Fatty acid ethyl esters in the blood as markers for ethanol intake. JAMA. 1996;276:1152-6.

4. Himes SK et al. Validation of a novel method to identify in utero ethanol exposure: simultaneous meconium extraction of fatty acid ethyl esters, ethyl glucuronide, and ethyl sulfate followed by LC-MS/MS quantification. Anal Bioanal Chem. 2014;406:1945-55.

5. Ulrich L, Cramer Y, Zink P. Die Berücksichtigung individueller Parameter bei der Errechnung des Blutalkoholgehaltes aus der Trinkmenge. Blutalkohol. 1987;24:192-8.

6. Aderjan R et al. Richtlinien zur Bestimmung der Blutalkoholkonzentration (BAK) für forensische Zwecke. Blutalkohol. 2011;48:137-43.

7. US Department of Health and Human Services FDA. Guidance for industry: bioanalytical method validation. FDA. 2001. http://www. fda.gov/downloads/Drugs/Guidances/ucm070107.pdf. Accessed 11 Nov 2015.

8. Winkler M et al. Detection of ethyl glucuronide in blood spotted on different surfaces. Forensic Sci Int. 2011;210:243-6.

9. Bakhireva LN et al. The feasibility and cost of neonatal screening for prenatal alcohol exposure by measuring phosphatidylethanol in dried blood spots. Alcohol Clin Exp Res. 2013;37:1008-15.

10. Faller A et al. LC-MS/MS analysis of phosphatidylethanol in dried blood spots versus conventional blood specimens. Anal Bioanal Chem. 2011;401:1163-6.

11. Auwärter Vet al. Fatty acid ethyl esters in hair as markers of alcohol consumption. Segmental hair analysis of alcoholics, social drinkers, and teetotalers. Clin Chem. 2001;47:2114-23.

12. Auwärter V. Fettsäureethylester als Marker exzessiven Alkoholkonsums - Analytische Bestimmung im Haar und in Hautoberflächenlipiden mittels Headspace-Festphasenmikroextraktion und Gaschromatographie-Massenspektrometrie. In: MathematischNaturwissenschaftlichen Fakultät I2006, Humboldt-Universität zu Berlin. p. 181. 